Facsimile Price $\$$

Microfilm Price \$

Available from the

Office of Technical Services

Department of Commerce

Washington 25, D. C.

\title{
MICROSPOROGENESIS AND EMBRYOGENESIS IN QUERCUS
}

This paper was submitted for publication in the open literature at least 6 months prior to the issuance date of this Microcard. Since the U.S.A.E.C. has no evidence that it has been published, the paper is being distributed in Microcard form as a preprint. by

G. R. STATRS*,**

Yale University, School of Forestry, New Haven, Conn.

Biology Department, Brookhaven National Laboratory, Upton, N.Y.***

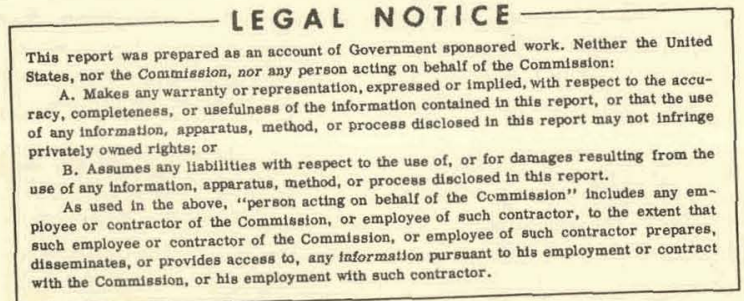

* Work performed under Contract No. AT (30-1) 2755, Atomic Energy Commission, Division of Biology and Medicine, Biology Branch; awarded to Dr. Franģois Mergen, Yale University, School of Forestry.

** Present address: State University of New York, College of Forestry, at Syracuse University, Syracuse, New York.

This laboratory is operated under the auspices of the U.S. Atomic Energy Commission.

The article is part of a study on radiation effects in oaks carried out by the author in partial fulfillment of requirements for the Ph.D. degree at Yale University. 


\section{DISCLAIMER}

This report was prepared as an account of work sponsored by an agency of the United States Government. Neither the United States Government nor any agency Thereof, nor any of their employees, makes any warranty, express or implied, or assumes any legal liability or responsibility for the accuracy, completeness, or usefulness of any information, apparatus, product, or process disclosed, or represents that its use would not infringe privately owned rights. Reference herein to any specific commercial product, process, or service by trade name, trademark, manufacturer, or otherwise does not necessarily constitute or imply its endorsement, recommendation, or favoring by the United States Government or any agency thereof. The views and opinions of authors expressed herein do not necessarily state or reflect those of the United States Government or any agency thereof. 


\section{DISCLAIMER}

Portions of this document may be illegible in electronic image products. Images are produced from the best available original document. 


\section{MICROSPOROGENESIS AND EMBRYOGENESIS IN QUERCUS}

\section{INTRODUCTION}

An increasing interest in hardwood tree genetics has created a need for basic cytological studies in many of our native species. While a great deal of work has been accomplished in the silviculture of hardwoods in the past decade, little data is available on the cytology of flowering.

The genus Quercus constitutes the most 1 mportant aggregation of hardwoods on the North American continent, and timber supplied from this group is second only to the conifers in total production (Harlow and Harrar, 1950; U.S. Forest Service, 1958). Taxonomically the genus is 1 arge, containing approximately 80 species that are indigenous to the United States, with a great many natural hybrids between species. The genus is divided into two subgenera: Lepidobalanus, commonly called the "white oak" group, and Erythrobalanus, referred to as the "red or black oaks". Alluugh many disimilaritios are found between the two groups, the major difference of interest to this study is the time required for seed maturation. The white oak group matures seed in one growing season, while that of the red oaks requires two seasons. In the second group pol1en is shed and germinates on the receptive stigma in the spring; but fertilization and subsequent embryo maturity are delayed until the second growing season following pollination. 
In this respect the seed cycle in the subgenus Erythrobalanus is similar to that found in the genus Pinus.

Sexual reproduction in Quercus was first described in detail by Conrad (1900). Additional studies of embryo development have been reported for the following species: Quercus ilex (Corti 1959), Quercus aegilops (Scaramuzzi 1960), and Quercus trojana (Bianco 1961). In addition to these studies the development of the embryo sac in Quercus robur has been investigated by Bagda (1952) and Hjelmqvist (1953); the morphology of oak flowering and seed development in Quercus by Langdon (1939), and Turkel et a1. (1955). Sharp et al. (1961) reported on the staminate flowering of severai white oaks. A summary of genetic investigation in Quercus was reported in 1955 by Irgens-Mo11er, and the reader is referred to this report for a review of associated 1iterature to that date.

The present investigation was undertaken (1) to define the norm in species to be utilized later in a study concerning the effect of gamma radiation on reproductive structures, and (2) to contribute to an understanding of microsporogenesis, embryogenesis, and floral phonology in the three oak species under investigation.

\section{MATERIAL IND METHODS}

Two species from the Erythrobalanus group - Quercus coccinea, Muench., and Quercus ilicifolia, Wang., and one from tho Lepidobalanus group - Quercus alba, Linn., were 
selected for investigation. The sample trees were growing under natural forest conditions near the Brookhaven National Laboratory, Long Island, New York. Determination of microspore development was made by the smear technique, while macrospore and embryo development were followed by serial sectioning. Collections for microsporogenesis were made from cut branches brought into a greenhouse approximately two wooks prior to the breaking of dormancy in the spring. Male buds were fixed at 12-hour-intervals through the meiotic stages, and then daily from the quartet stage to pollen shedding. In addition, collections were made at two-day-intervals from trees growing under natural conditions. The dates of pollen shedding were recorded as the mean time of pollen dispersion in the population examined.

$$
\text { Preliminary investigation of microsporogenesis from }
$$
previous cytological work with the genus had indicated good fixation with either Newcombers fixative, or a solution of 3 parts propionic acid to 1 part 95 percent alcohol. In the work reported here all collections were fixed in Newcombers solution and stored at $40^{\circ} \mathrm{C}$ prior to observation. Staining trials were conducted with reulgen, aceto carmine, and propionic carmine, singly and in combination. From these experiments it was determined that adequate staining is obtained with propionic carmine. The staining results obtained were controlled by heat differentiation; observations and photomicrographs were made from smear preparations without further treatment. 
Female flowers were collected at five-day-intervals following pollination, fixed in F.A.A. and stored at $4^{\circ} \mathrm{C}$ prior to sectioning. The material was embedded in paraffin following an ethyl alcohol-chloroform dehydration serios, and serial sections were cut at $8 \mathrm{microns.} \mathrm{Because} \mathrm{the}$ cupule surrounding the oviles was difficult to cut, the ovules and developing embryos were excised prior to embedding. All sections were stalned with a combination of safranin and fast green.

\section{OBSERVATION AND DISCUSSION}

\section{Floral Structures}

The male flowers of Quercus develop on long slender catkins, borne either in the scale-1eaf axils of the current vegetative buds or in separate male buds. Figure 1A shows the catkins from a malo bud of Quercus about 4 days prior to pollen shedding. The female flowers are located in the axils of the new leaves; examples of Quercus ilicifolia are shown in 1B; the upper two floral groups are normal while a flower borne in the leaf axil on the lower left contains a rudimentary vegetative leaf. Such variation was occasionally observed in all three species as well as rudimentary pistillate structures in staminate inflorences of Quercus ilicifolia. The frequency of variant forms was extremely low and no attempt was made to quantify their existence. Previous reports of anomalous flowering in Quercus have been made by Minina (1951), and by Scaramuzzi (1958). As previously mentioned the seed from 
individuals in the Erythrobalanus subgenera requires two years to mature; a developing acorn of Quercus ilicifolia from the previous poliination season (1961) is shown below the recently poliinated (1962) fomale structures of the current years primordia (1C). The internal acorn structure at fertilization is indicated by the excised ovules (1D) and by a cross section of the ovules in 1E. In the usual situation only one embryo develops within a single ovule and the remaining 5 orules abort. A cross section of the developing acorn (IF) is shown; the section is cut through the developing cotyledons.

\section{Microsporogenesis}

Meiotic activity in Quercus coccinea and Quercus licifolia begins with early bud swell and microspores were at the quartet stage by the time catkin emergence could be seen. In Quercus alba meiosis was delayed until the catkin had elongated slightly between the bud scales. Under natural conditions meiotic activity in Quercus alba occurred about two wooks aftor the other two species.

The chromosomes of oak are small, a feature they share with most of the other woody angiosperms. At meiotic metaphase the length of the bivalents varied from approximately 4 microns down to about 1.5 microns. Chromosome number for all three species investigated was $2 n=24$. All other recent reports for Quercus have confirmed 24 as the diploid number; an erroneous report of $2 n=48$ for Quercus 
dentata (see Darlington and Wylie 1955) has since been corrected by Santamour (1962). In all three species, divisions were regular and no aberrations were observed. The meiotic chromosomes were similar for the three species; because of this similarity only photomicrographs of Quercus alba are presented for iliustration.

Figure 2 A depicts a microsporocyte during interphase prior to meiotic division. The cell is angular in outline and the nucleus is large, with a prominent nucleolus. The progressive stages of prophase were well defined and despite the small chromosome size, chromonemata (2B) were quite visible. At this stage chromosome pairing could be observed, as well as association of the two longer chromosomes with the nucleolus. The nucleolus persisted through late diakinesis $(2 C)$, the time at which chiasmata could be observed in terminalization. Although not the goal of this study it would appear that observations of diakinesis could contrubute to a physical knowledge of crossing over in the oaks. Bivalent formalion was regular in all three species and at metaphase I (2D) a certain amount of secondary association was observed. This association was not consistently in 6 groups but was more frequent than would be expected from random distribution. Natividade (1937) has discussed the relation of secondary association to the phylogenetic origin of Quercus. At anaphase I (2E) the smalier chromosomes were often 
slightly precocious in migration to the poles. A telophase I (2F) is illustrated and interphase between the two melotic divisions shows well defined resting nuclei ( $2 G)$. An early anaphase II (2H) and telophase II (2I) are shown and indicate the regularity of these divisions. No precocious movement of the smaller chromosomes was observed at anaphase II. Cytokinesis took place following anaphase II and the resulting quartet of microspores is shown in $2 \mathrm{~K}$. Maturation of the pollen grain occured during elongation of the catkin. The gametic division into a generative and tube nucleus occurred just prior to pollen shedding. These two nuclei are indicated in $2 L$ at the completion of the first vegetative division. The generative nucleus is above the tube nucleus in the photomicrograph and shows a more heterogeneous staining than the more rounded tube nucleus. Further development of the generative nucleus results in an elongated shape similar to the type common in most angiosperm plants. Mature pollen (2M) is shed and doposited on the receptive stigmas in the bi-nucleate condition.

Pollen of Quercus ilicifolia and Quercus coccinea was shed on May 10; while that of Quercus alba was shed approximately two weeks later on May 25. The majority of polien from a single tree was shed during a 48 hour period; however, due to micro climatic differences there was a range of one week within the populations observed. Embryogenesis

Early ovile development began approximately 13 months 
after pollination in the subgenera Erythrobalanus and about one month after pollination in the Lepidobalanus group. Although there is a major timing difference between the two groups prior to fertilization the subsequent embryo developmental stages are essentially parallel. Pollination occurred some two to four weeks 1 ater in Quercus alba than in Quercus coccinea or Quercus ilicifolia and the embryo development and seed maturity were similarly delayed. Aside from the major difference in pre-fertilization timing subsequent development of the oak reproductive structures appears to be relatively uniform from a cytological or morphological viewpoint. For this reason embryogenesis and developmental chronology will be discussed only for Quercus coccinea. The developmental timing in Quercus ilicifolia was similar while that in Quercus alba was delayed as mentioned above. Thus one may relate the three species inferentially to the following discussion. Embryo development within a species varied betwoen individual trees and to a lesser degree within crown positions on the same tree. The following discussion will include dates of observation as: average values from two control treos growing on slightly dissimilar sites. Values for the entire population would not be expected to vary more than a few days from this mean; although a phenological discrepancy may be found in year-to-year consideration.

Ovules from collections made on June 1 , indicated a 
pre-meiotic condition (Figure 3A) with integuments well defined and the micropylar area still quite broad. By June 6, meiosis had taken place and the integuments were enlarged so that only a narrow micropylar canal remained (3B). From serial sections it was observed that the initial embryo sac development originated from a monosporic condition. Previous reports of a tetrasporic embryo sac development have been reported (Conrad 1900, Bagda 1952), however, Hjelmqvist (1953) has investigated the development in Quercus robur and found it to be monosporic. In addition the photomicrographs published by Corti (1959) of macrosporogenesis in Quercus ilex serve to confirm a monosporic origin.

Subsequent embryo sac development was quite rapid following completion of meiotic activity. Collections made on June 18, showed the embryo sac at the two-nucleate condition (3C) while those made on June 21, contained the mature sac (3D). At maturity the embryo sac contained the 8 nuclei of the normal angiosperm type. The section shown indicates only the diploid fusion nucleus prior to initiating the free nuclei stage of endosperm development depicted in 3E. Endosperm formation is well advanced prior to the begining of embryo growth. From observation of serial sections it could be seen that several ovules within a single seed contained developing endosperm prior to embryo development. Therefore, it would seem that definitive ovule dominance, resulting in single embryo 
formation within a seed, occurs during the early embryo growth and is not a function of pollination or fertilization. Multiple embryo occurrence in oak seed has been discussed by several. suthors (Coker 1904, Harvey 1917, Bucholz 1941, Johnsson 1946, Almeida 1951, Hosner 1957). Johnsson (1946) reported a few polyploids (less than 1 percent) among Quercus robur seedlings grown from multi-seeded acorns. Ho suggested that the polyploids observed resulted from abnormal embryo development. In the observations reported herein mutiple embryos resulted from fertilization and embryo development in separate ovules and did not indicate abnormal development per se. The frequency of twin seediings was low and was not related to any particular tree in the control group. However, Coker (1904) reported the condition to be associated with a single tree, a factor which would give evidence of genetic control.

The early developing embryo on June 28 , is seen in $3 F$, and the average stage of development by July 15, is indicated in 3G. At the latter time cotyledons begin to differentiate and organization of protoderm and apical primordia are in evidence. By July 29, the colyledons were well formed and further differentiation of the apical meristem had occurred. At this time initiation of the procambium region is well defined (3H). By August 26, the embryo is morphologically mature with procamium, apical meristematic regions and the root cap completely formed (3I). Following this stage 
only a slight enlargement was observed prior to seed shedding.

\section{SUMMARY}

Representative species from two subgenera in the genus Quercus were examined for floral structure and phenology, microsporogenesis, and embryogenesis. The species selected for investigation were: Quercus alba in the Lepidobalanus subgenera, and Quercus coccinea and Quercus ilicifolia from the Erythrobalanus group. Photographs of flowering and photomicrographs of microsporogenesis and embryogenesis are used for illustration. During the course of the investigation the following observations were made.

1. The male flowers of the three species are borne on catkins which derelop in the scale leaf axils of the current vegetative bud or in separate male buds. Meiosis occurred in the spring at the begining of bud enlargement; division figures were regular in all the material observed. A haploid chromosome number of 12 was confirmed for the three species.

2. Pollen was shod on May 10, 1962, from trees of Quercus coccinea and Quercus ilicifolia; and on May 26, 1962 from Quercus alba.

3. The female flowers are located in the axils of the new leaves. Seed development requires one growing season in Quercus alba, but two growing seasons are required to mature seed of Quercus coccinea and Quercus ilicifolia. The chronology of embryo development was similar for Quercus coccinea and Quercus ilicifolia; 
ombryo development of Quercus alba was about two weeks behind that of the other two species.

4. Definition of ovule dominance within a seed occurred at the time of early embryo development. Failure of this physiological expression of dominance results in multiseeded acorns. No abnormal embryogenesis per se was observed in relation to multiple embryo development.

\section{ACKNOWLEDGEMENTS}

The author wishes to thank Dr. Francols Mergen of the Yale School of Forestry, Yale University, and Dr. Arnold Sparrow of the Brookhaven National Laboratory, for their valuable suggestions during this study. Technical assistance by Mr. A. Potracco is also gratefully acknowledged. 


\section{BIBLIOGRAPHY}

1. Almeida, J.L. Ferreira De. 1951. Polispermia em Quercus suber L. Agron. 1usit. 13: 213-219.

2. Bagda, H. 1952. Untersuchungen uber den weiblichen Gametophyten der Valonea-eiche (Quercus macrolepis $\mathrm{Ky}$. ) Istanbu1. U. Fen. Faku1. Mecmuasi B 17: 77-92.

3. Bianco, P. 1961. Ricerche sul ciclo riproduttivo di specie del genere Quercus della flora italiana. VI. Contributo alla biologia di Quercus trojana Webb. in Pug1ia. Ann. Accad.. Ital. Sci. For. 10: 59-96.

4. Bucholz, J.T. 1941. Multi-seeded acorns. Trans. I11. Acad. of Sci. 34: 99-101.

5. Coker, W.C. 1904. Mu1ti-seeded acorns. Bot Gaz. 37 : $61-62$.

6: Conrad, A.H. 1900. A contribution to the life history of Quercus. Bot Gaz. 29: 408-418.

7. Corti, R. 1959. Ricerche sul ciclo riproduttivo di specie del genere Quercus della flora italiana. IV. Osservazioni sulla embrioligia e sul ciclo riproduttivo in Quercus ilex, L. Ann. Accad. Ital. Sci. For. 8: 19-42.

8. Darlington, C.D. and A.P. Wylie. 1955. Chromosome atlas of flowering plants. George Allen and Unwin Ltd., London $519 \mathrm{pp}$.

9. Harlow, W.M. and E.S. Harrar. 1950. Textbook of dendrology. Third edition, McGraw-Hill Book Co. Inc. New York. 555 pp.

10. Harvey, L.H. 1917. Polyembryony in Quercus. Mich. Acad. of sci. Report 19: 329-384.

11. Hjelmqvist, H. 1953. The embryo sac development of Quercus robur, L. Phytomorphology 3: 377-384.

12. Hosner, J.F. 1959. Multi-seeded acorns. Jour. For. 57: 127 .

13. Irgens-Molier, H. 1955. Forest tree genetics research: Quercus L. Econ. Bot. 9: 53-71.

14. Johnsson, H. 1946. Chromosome numbers of twin plants of Quercus robur and Fagus silvatica. Hereditas 32: $469-472$.

15. Langdon, LaDema M. 1939. Ontogenetic and anatomical studies of the flower and fruit of the Fagaceae and Jugl and aoeae. Bot Gaz. 101: 301-327: 
16. Minina, E.G. 1951. Anomal jnoe cretenie duba. Priroda, Moskva 40: 50-52. (Abstr. in For Abstr. 13, 1951-52.)

17. Natividade, J.V. 1937. Investigacoes citologicas nulgumas especies e hibridos do genero Quercus. Publicacoes do Direccao Geral dos Servicos Fiorestals e Aquicolas 4: 7-80.

18. Santamour, F.S. 1962. The chromosome number of Quercus dentata. Morris Arboretum Bulletin 13: 28-30.

19. Scaramuzi, F. 1958. Osservazioni su anomalie dei flori in Quercus coccifera L. Nuovo. G. bot. ital. 45: 380-388.

20. Scaramuzzi, F. 1960. Ricerche sul ciclo riproduttivo di specie del genere Quercus della flora itallana. V. Osservazioni sul ciclo riproduttivo e sulla embriologia di Quercus aegilops, L. Ann. Accad. Ital. Sci. For. 9: $289-322$.

21. Sharp, H.M. and H.H. Chisman. 1961. Flowering and fruiting in the white oaks. I. Staminate flowering through pollen dispersal. Ecology 42: 365-372.

22. Turkel, H.S.; A.L. Rebuck; and A.R. Grove, Jr. 1955. Floral morphology of white oak. Pa. State Univ. Buil. 593: $14 \mathrm{pp}$.

23. U.S. Forest Service. 1958. Timber resources for America's future. U.S.D.A. Forest Service Report No. 14. 713 pp. 
FIGURE 1. Floral structures and early acorn development in Quercus. (A) Male flowers 4 days before pollen shedding. (B) Female flowers at the time of pollination. (C) Developing 1 year acorn pollinated in 1961 below the flowers of the current (1962) season. Excised ovules at the time of fertilization are shown in (D) and a cross section in (E). The developing embryo within one ovule is shown (F); the section is cut through the colyledons of the embryo. Scale for (A) to (C) is in $\mathrm{mm}$. 

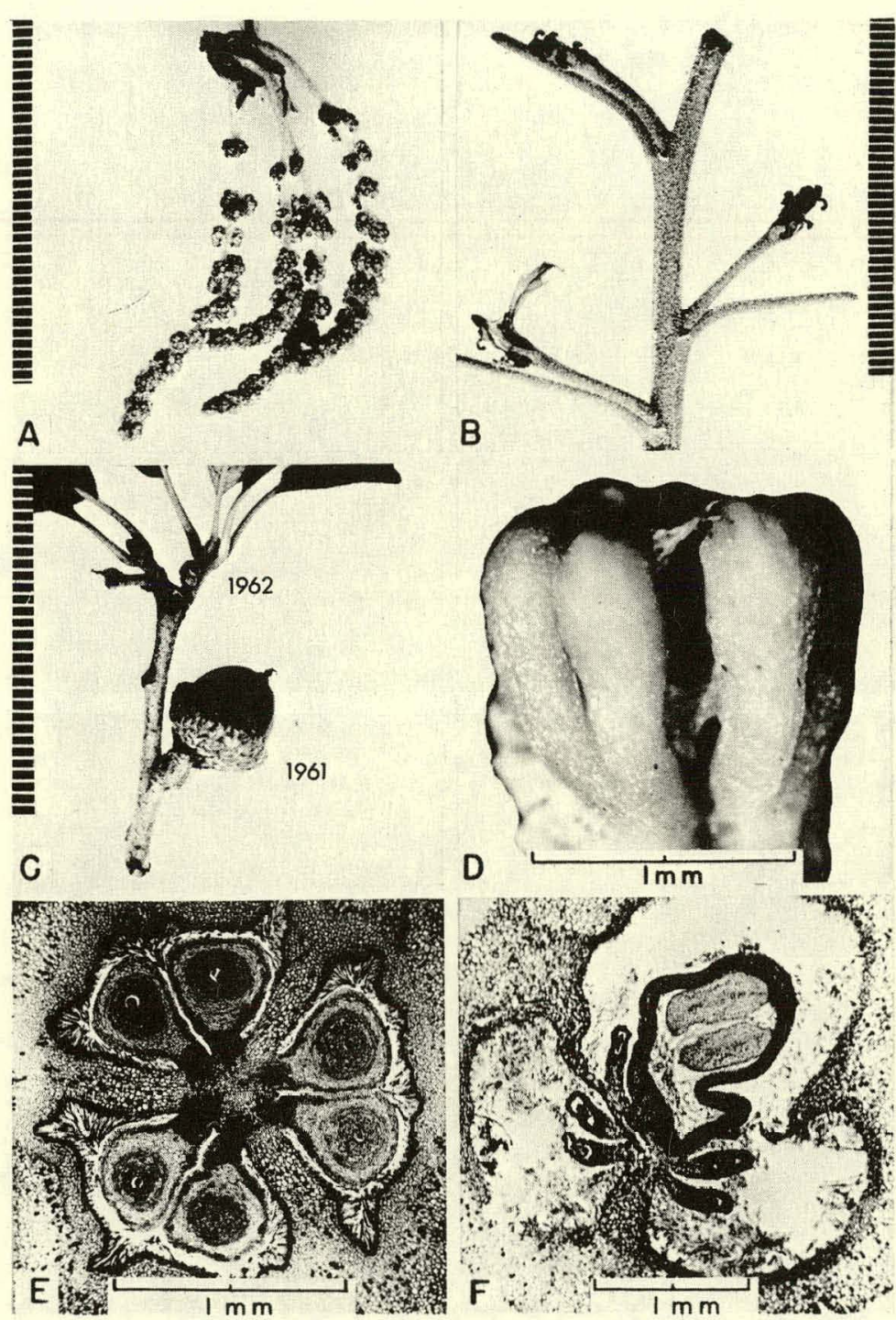

FIGURE I 
FIGURE 2. Microsporogenesis in Quercus alba.

(A) Microsporocyte. (B) Pachytene, two of the larger chromosomes are associated with the nucleolus. (C) Diakinesis. (D) Metaphase I. (E) Anaphase I, the smaller chromosomes are precocious in going to the poles. (F) Telophase I. (G) Interphase between the meiotic divisions, a distinct nuclear membrane is formed. (H) Early anaphase II. (I) Telophase II, followed by cytokinesis and formation of the quartet of pollen grains seen in $(K)$. At $(L)$ the generative and tube nucleus are shown prior to shedding of the mature bi-nucleate grain seen in (M). The scale for (A) to (K) is shown at (A). The nuclei in (L) are pictured at a slightly larger magnification, the mature pollen grains (M) averaged 30 microns in diameter. 


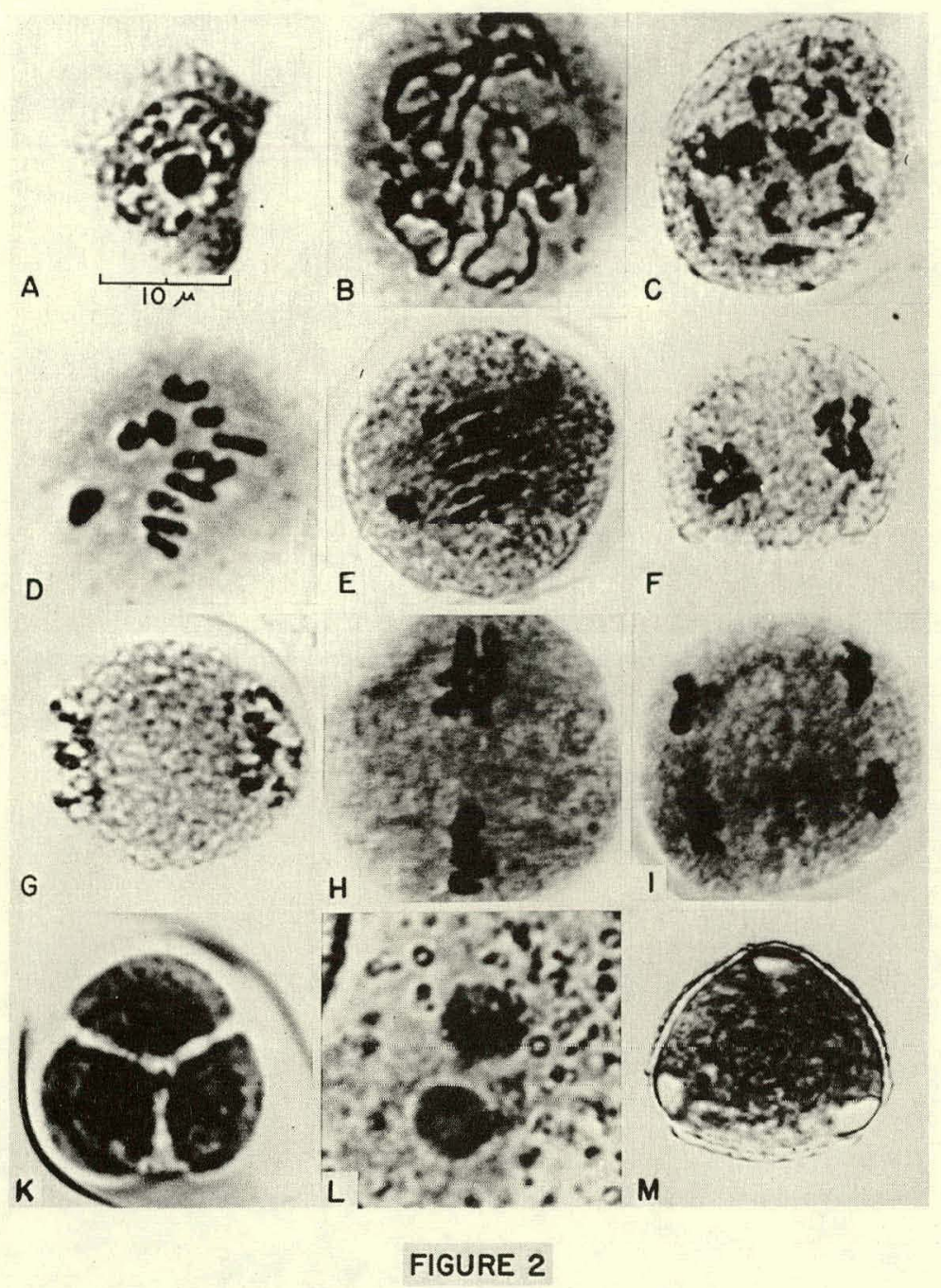


FIGURE 3. Outline of embryogenesis in Quercus coccinea. (A) Longitudenal section of a female flower prior to megasporogenesis. (B) Condition of the ovule during meiosis. the integuments have enlarged leaving a narrow micropylar canal. (C) The two-celled stage of embryo sac development. (D) A mature embryo sac showing the fusion nucleus prior to division leading to the free nuclei stage of endosperm formation seen in (E). An early developing embryo is shown in (F) and at the time of begining cotyledonary differentiation in (G). The appearance of provascular tissue is shown in (H) and the mature embryo at (I). 


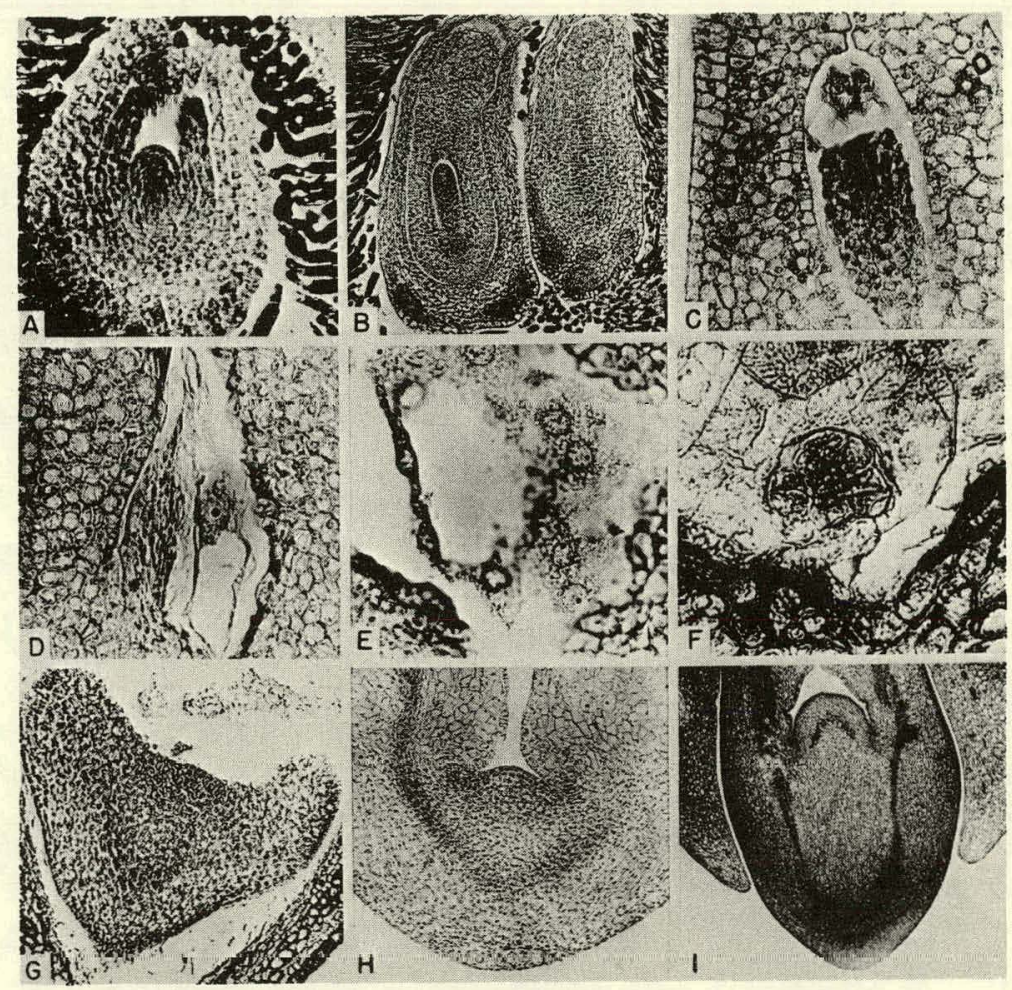

FIGURE 3 